\title{
A POLÍTICA NACIONAL DE EDUCAÇÃO AMBIENTAL E OS SABERES AMBIENTAIS NA CONSTRUÇÃO DO CONSUMIDOR-CIDADÃO
}

Naína Ariana Souza Tumelero ${ }^{1}$

Carolina Medeiros Bahia ${ }^{2}$

Resumo: $O$ presente artigo tem por objetivo analisar a Política Nacional de Educação Ambiental (PNEA) e a sua relação na racionalização dos "saberes ambientais" na construção do consumidor-cidadão. O estudo analisa a Política Nacional de Educação Ambiental, aprofundando 0 estudo da constitucionalização da Educação Ambiental e da Lei n. 9.795/99. A Educação Ambiental é tida como uma educação para a vida e uma forma de construir a racionalização dos "saberes ambientais". Ao final, analisa-se a relação entre a Educação Ambiental e a construção de consumidores-cidadãos, enquanto cidadania baseada na consciência dos impactos do consumo no meio ambiente nesta, e nas próximas gerações. Ao final, aponta-se a necessidade de uma análise mais profunda entre cidadania e consumo, em que a liberdade e a racionalização das opções de compra, e a exigência quanto à qualidade do que se adquire, caracterizem-se como um novo tipo de consumidor, o denominado "consumidor-cidadão", que não deixa de ser um "ecoconsumidor", na medida em que se vê como parte do todo global.

Palavras-chave: Educação Ambiental; Saberes Ambientais; Cidadania; Consumidor-Cidadão.

${ }^{1}$ Universidade Federal de Santa Catarina. E-mail: naina.tumelero@gmail.com. 


\section{Introdução}

Chegamos a um consenso de que o modo atual de produção e consumo extrapola a capacidade do nosso planeta, comprometendo não somente esta geração, mas especialmente as gerações futuras.

Com essa consciência, algumas providências foram tomadas no que concerne à legislação. Dessas, ganham destaque no presente trabalho a constitucionalização da Educação Ambiental e a Política Nacional da Educação Ambiental (PNEA).

A Educação Ambiental é estabelecida com um rol de princípios e objetivos, e defendida, neste presente estudo, como uma forma de racionalização dos "saberes ambientais", promovendo uma maior conscientização nos estudantes sobre as suas escolhas, e o impacto delas, especialmente no consumo, tendo em vista que os educandos de hoje, são, e serão os consumidores de amanhã.

Nesta sociedade (de risco), as figuras do cidadão e do consumidor estão profundamente atreladas, sendo impossível a dissociação. Assim, notase comportamentos distintos de consumo, como o consumo verde e o sustentável, que, quando devidamente interpretados pela visão da cidadania, chegam ao eco consumo, na figura do, aqui defendido, consumidor-cidadão.

O objetivo do presente estudo, portanto, é analisar a PNEA e a sua relação na racionalização dos "saberes ambientais" na construção do consumidor-cidadão. Para tanto, encontra-se subdividido em três principais partes, iniciando a análise pela Política Nacional de Educação Ambiental, trecho destinado ao aprofundamento do estudo da constitucionalização da Educação Ambiental e da Lei n. 9.795/99; avançando à segunda parte, cujo objetivo é contextualizar a Educação Ambiental como uma educação para a vida, utilizando-se, dentre outros autores, do marco teórico de Enrique Leff, na racionalização dos saberes ambientais; e, por fim, a análise da relação entre a Educação Ambiental e a construção de consumidores-cidadãos, ou seja, uma cidadania baseada na consciência dos impactos do consumo no meio ambiente nesta, e nas próximas gerações.

A conclusão aponta a necessidade de uma análise mais profunda no sobre a relação entre cidadania e consumo, onde se nota um novo comportamento, advindo de um componente da cidadania, a liberdade e a racionalização das opções de compra, e a exigência quanto à qualidade do que se adquire, caracterizando assim o denominado "consumidor-cidadão", que não deixa de ser um "ecoconsumidor", na medida em que se vê como parte do todo global. 


\section{A política nacional de Educação Ambiental}

A Educação Ambiental tem o condão de preparar os cidadãos para as responsabilidades para com o meio ambiente, colocando-os em uma posição ativa na preservação ambiental e na garantia de vida às gerações futuras por meio da sustentabilidade.

Para iniciar o debate acerca da questão, cumpre resgatar a linha cronológica estabelecida por Portanova (2011, p. 148-149), que estabelece treze marcos da regulação da educação ambiente, desde o âmbito internacional, até o nacional, quais sejam: 1) Programa Internacional de Educação Ambiental, em 1975 (Sérvia e Belgrado); 2) Aprovação dos cursos de pós-graduação em ecologia, 1976; 3) Conferência em Tbilisi- Georgia ,1977; 4) Inclusão dos conteúdos nas engenharias, Brasil, 1978; 5) Seminário latinoamericano na Costa Rica, 1979; 6) Brasil incluí conteúdos ecológicos nos $1^{\circ} \mathrm{e}$ 2 o graus, 1985; 7) Congresso Internacional em Moscou, 1987; 8) Constituição da República Federativa do Brasil, 1988; 9) Conferência Internacional de Illinois- EUA, 1989; 10) Declaração Mundial sobre Educação para Todosconferência em Jontien, Tailândia 1990; 11) Educação Ambiental permeando todo o currículo em todos os níveis de modalidades no Brasil 1991; 12) Conferência da ONU- Meio Ambiente e Desenvolvimento- RIO- 92. Carta Brasileira para a Educação Ambiental, 1992; - Brasil- Portaria n. 773/93 do MEC, 1993; 13) Programa Nacional de Educação Ambiental, 1994; 14) Câmara de Educação Ambiental no CONAMA, 1995; 15) Lei n. 9.279/1996 3; 16) Conferência Internacional Thessaloniki- Grécia, 1997; 17) Capacitação de Multiplicadores, 1998; 18) Lei n. 9.795/99, Política Nacional de Educação Ambiental, 1999.

No Brasil, o movimento de Educação Ambiental uniu-se à constitucionalização do meio ambiente ${ }^{4}$. Mesmo que desde cedo houvesse legislações com a premissa de preservar o meio ambiente, a "ecologização da Constituição" 5 foi constatada apenas nos anos 70 e seguintes e teve como estopim, a crise ambiental instalada após a Segunda Guerra. Este, como declara Benjamin (2012, p. 86-87) foi um "daqueles raros momentos, que ocorrem de tempos em tempos, em que o senso de civilização é redefinido 6", pois apenas desta época em diante o ambiente passou a ser reconhecido como merecedor de tutela maior pelos sistemas constitucionais.

Para Leite (2012, p. 168), resta claro que o ambiente é tratado como bem de interesse comum da coletividade no regime constitucional brasileiro,

\footnotetext{
${ }^{3}$ Regula direitos e obrigações relativos à propriedade industrial.

4 "Olhando em volta, é seguro dizer que a constitucionalização do ambiente é uma irresistível tendência internacional, que coincide com o surgimento e consolidação do Direito Ambiental" (BENJAMIN, 2012, p. 87).

${ }^{5}$ Termo cunhado por Benjamin, 2012, p. 85.

${ }^{6}$ Expressão do geógrafo Carl O. Sauer.

Revbea, São Paulo, V. 13, № 1: 124-139, 2018.
} 
compartilhando o Estado e a coletividade, a responsabilidade de sua proteção ${ }^{7}$. Neste sentido, Benjamin (2012, p.101), destaca que:

A verbalização do discurso constitucional de proteção do ambiente não anuncia, como desiderato principal, um non facere; ao contrário, inegavelmente prega e exige prestações positivas a cargo do Estado, mensagem irrecusável que vem em reforço dos deveres infraconstitucionais de garantia pelas autoridades públicas dos processos ecológicos essenciais.

No que concerne à legislação infraconstitucional, Rodrigues e Fabris (2011, p.12) destacam algumas iniciativas que vão de encontro à constitucionalização do meio ambiente e, por conseguinte, da Educação Ambiental, sendo elas: Código Florestal (Lei 12.651/2012); Código de Águas (Decreto 24.643/1934); Código de Pesca (Lei 11.959/2009); Código de Proteção à Fauna (Lei 5.197/1967); Política Nacional do Meio Ambiente (Lei 6.938/81), Lei da Ação Civil Pública (7.347/85); e a Lei dos crimes ambientais (Lei 9.605/1998).

Especificamente na Constituição Federal, destaca-se o capítulo VI, "Do meio ambiente", composto, basicamente, pelo artigo 225, que garante a todos o "direito ao meio ambiente ecologicamente equilibrado, bem de uso comum do povo e essencial à sadia qualidade de vida, impondo-se ao Poder Público e à coletividade o dever de defendê-lo e preservá-lo para as presentes e futuras gerações". Artigo este que, em seu parágrafo primeiro, inciso VI, incumbe ao Poder Público a promoção da "Educação Ambiental em todos os níveis de ensino e a conscientização pública para a preservação do meio ambiente". Além deste capítulo, Rodrigues e Fabris (2011, p. 12-13) destacam outras referências explícitas, trazidas meramente a título de exemplo, como, o artigo $5^{\circ}$, inciso LXXIII ${ }^{8}$, artigo $20^{9}, 23{ }^{10}, 170$, inciso $\mathrm{VI}{ }^{11}, 186$, inciso $\mathrm{II}^{12}$.

\footnotetext{
7 Art. 24. Compete à União, aos Estados e ao Distrito Federal legislar concorrentemente sobre: [...] VIII responsabilidade por dano ao meio ambiente, ao consumidor, a bens e direitos de valor artístico, estético, histórico, turístico e paisagístico;

8 "Qualquer cidadão é parte legítima para propor ação popular que vise a anular ato lesivo ao patrimônio público ou de entidade de que o Estado participe, à moralidade administrativa, ao meio ambiente e ao patrimônio histórico e cultural, ficando o autor, salvo comprovada má-fé, isento de custas judiciais e do ônus da sucumbência".

${ }^{9}$ Art. 20. São bens da União: [...] II - as terras devolutas [...]; III - os lagos, rios e quaisquer correntes de água em terrenos de seu domínio [...]; IV - as ilhas fluviais e lacustres nas zonas limítrofes com outros países [...]; V - os recursos naturais da plataforma continental e da zona econômica exclusiva; VI - o mar territorial; [...] IX - os recursos minerais, inclusive os do subsolo; [...] XI - as terras tradicionalmente ocupadas pelos índios.

${ }^{10}$ Art. 23. É competência comum da União, dos Estados, do Distrito Federal e dos Municípios: [...]VI proteger o meio ambiente e combater a poluição em qualquer de suas formas; VII - preservar as florestas, a fauna e a flora[...].

${ }^{11}$ Art. 170 CF. A ordem econômica, fundada na valorização do trabalho humano e na livre iniciativa, tem por fim assegurar a todos existência digna, conforme os ditames da justiça social, observados os seguintes princípios: [...] VI - defesa do meio ambiente, inclusive mediante tratamento diferenciado conforme o impacto ambiental dos produtos e serviços e de seus processos de elaboração e prestação[...].
} 
A fim de alcançar o objetivo do presente estudo, cabe adentrar de modo mais profundo à Política Nacional de Educação Ambiental (PNEA), lei número 9.795/99, que veio para ratificar a premissa constitucional de proteção ambiental, definida como um conjunto de "processos por meio dos quais o indivíduo e a coletividade constroem valores sociais, conhecimentos, habilidades, atitudes e competências voltadas para a conservação do meio ambiente, bem de uso comum do povo, essencial à sadia qualidade de vida $\mathrm{e}$ sua sustentabilidade (art. $\left.1^{\circ}\right)$ ". De acordo com Rodrigues e Fabris (2011, p. 31) "o que busca a legislação é que seja desenvolvida uma nova consciência, através de uma Educação Ambiental racional, contagiante e eficaz que permita tentar reverter o quadro de degradação ambiental do qual todos fazem parte".

A PNEA, em seu artigo $2^{\circ}$, também trata de garantir a obrigatoriedade da Educação Ambiental, considerada "um componente essencial e permanente da educação nacional13" que deve estar presente em todos os níveis e modalidades do processo educativo, tanto em caráter formal ${ }^{14}$ como nãoformal 15. Além disso, cumpre destacar que, conforme o artigo $3^{\circ}$, as responsabilidades para a efetivação da PNEA na caracterização de um processo educativo mais amplo não são apenas do Poder Público (art. 3o, inciso I), mas também das instituições educativas (art. 3ำ, inciso II), dos órgãos integrantes do Sistema Nacional de Meio Ambiente - Sisnama (art. 3ํㅡ, inciso III), dos meios de comunicação de massa (art. $3^{\circ}$, inciso IV), das empresas, entidades de classe, instituições públicas e privadas (art. $3^{\circ}$, inciso V) e da sociedade como um todo (art. $3^{\circ}$, inciso $\mathrm{VI}$ ). Ou seja, todos são responsáveis.

Prosseguindo no estudo da referida Lei destaca-se, especialmente, seus princípios e objetivos, sendo que, no que concerne ao primeiro, o artigo $4^{\circ}$ deixa claro quais são os princípios básicos da Educação Ambiental:

Art. 4ํㅗ̃o princípios básicos da Educação Ambiental:

I - O enfoque humanista, holístico, democrático e participativo;

II - A concepção do meio ambiente em sua totalidade, considerando a interdependência entre o meio natural, o socioeconômico e 0 cultural, sob 0 enfoque da sustentabilidade;

III - O pluralismo de ideias e concepções pedagógicas, na perspectiva da inter, multi e transdisciplinaridade;

IV - A vinculação entre a ética, a educação, o trabalho e as práticas sociais;

\footnotetext{
12 Art. 186. A função social é cumprida quando a propriedade rural atende, simultaneamente, segundo critérios e graus de exigência estabelecidos em lei, aos seguintes requisitos: [...]II - utilização adequada dos recursos naturais disponíveis e preservação do meio ambiente;

13 LDB- Lei 9.394/96- Art. 21. A educação escolar compõe-se de: I - educação básica, formada pela educação infantil, ensino fundamental e ensino médio; II - educação superior.

${ }^{14}$ Art. 9 PNEA Entende-se por educação ambiental na educação escolar a desenvolvida no âmbito dos currículos das instituições de ensino públicas e privadas [...].

${ }^{15}$ Art. 13 PNEA. Entendem-se por educação ambiental não-formal as ações e práticas educativas voltadas à sensibilização da coletividade sobre as questões ambientais e à sua organização e participação na defesa da qualidade do meio ambiente.

Revbea, São Paulo, V. 13, No 1: 124-139, 2018.
} 
V - A garantia de continuidade e permanência do processo educativo;

VI - A permanente avaliação crítica do processo educativo;

VII - A abordagem articulada das questões ambientais locais, regionais, nacionais e globais;

VIII - O reconhecimento e o respeito à pluralidade e à diversidade individual e cultural.

Para melhor compreender o inciso III, que trata do pluralismo de ideias nas perspectivas inter, multi e transdisciplinares, cumpre resgatar 0 ensinamento de Rodrigues e Fabris (2011, p.25), de que a multidisciplinaridade pode ser entendida como a necessidade de conhecer os diferentes conceitos de uma mesma disciplina, ou, até mesmo, os diferentes conceitos de um mesmo objeto segundo diferentes disciplinas, porém, não representa uma preocupação em integrar e articular seus temas comuns entre as diversas disciplinas. Já, a interdisciplinaridade supera tal fragmentação, relacionando-o com a realidade, e, em relação à Educação Ambiental, mais especificamente às questões ambientais, "trata-se do intercâmbio entre disciplinas, o diálogo entre elas com o objetivo principal de aproximação à realidade". A última delas, a transdisciplinaridade ${ }^{16}$, possui um conceito mais amplo "porque ela tende a produzir uma compreensão nova da realidade dentre e à frente das disciplinas especializadas, com a compreensão da complexidade" (RODRIGUES; FABRIS, 2011, p.26).

Já, no concernente aos objetivos fundamentais da Educação Ambiental, o artigo 5으 da lei estabelece que:

Art. 5o São objetivos fundamentais da Educação Ambiental:

I - O desenvolvimento de uma compreensão integrada do meio ambiente em suas múltiplas e complexas relações, envolvendo aspectos ecológicos, psicológicos, legais, políticos, sociais, econômicos, científicos, culturais e éticos;

II - A garantia de democratização das informações ambientais;

III - O estímulo e o fortalecimento de uma consciência crítica sobre a problemática ambiental e social;

IV - O incentivo à participação individual e coletiva, permanente e responsável, na preservação do equilíbrio do meio ambiente, entendendo-se a defesa da qualidade ambiental como um valor inseparável do exercício da cidadania;

V - O estímulo à cooperação entre as diversas regiões do País, em níveis micro e macrorregionais, com vistas à construção de uma sociedade ambientalmente equilibrada, fundada nos princípios da liberdade, igualdade, solidariedade, democracia, justiça social, responsabilidade e sustentabilidade;

$\mathrm{VI}$ - O fomento e o fortalecimento da integração com a ciência e a tecnologia;

\footnotetext{
${ }^{16}$ Para maior compreensão, ver "Carta da Transdisciplinaridade, no Convento da Arrábida, em Portugal, no ano de 1994". 
VII - O fortalecimento da cidadania, autodeterminação dos povos e solidariedade como fundamentos para o futuro da humanidade.

A Educação Ambiental, de acordo com Derani (2011, p.44) foi pensada para ser construída além do processo de ensino, compreendendo a educação como formação, "um processo mais abrangente e mais lento do que o da simples instrução". Neste sentido, concordam Rodrigues e Fabris (2011, p.3132), ao ensinarem que a função da Educação Ambiental é a formação de uma consciência e de uma única ética ambiental, ou seja, o seu objetivo é formativo, e não meramente informativo. Os autores (RODRIGUES; FABRIS, 2011, p.32) destacam ainda a necessidade de um "correto planejamento do processo, aliado a uma adequada preparação de todos aqueles que buscam formação para o exercício do magistério, em qualquer nível ou modalidade".

Conforme explicam Albuquerque e Fortes (2011, p.78), para romper com a ideia de superioridade que nos fez exploradores do meio ambiente, a consciência de que "pensar a favor da natureza é pensar a favor a favor de nossa própria espécie", já representa uma mudança de paradigma, porque, em realidade, "somos nós que dependemos integralmente de sua capacidade de manter a força que gera, opera e transforma a vida a cada segundo, através de processos físico-químicos que somente ocorrem pela conexão (im)perceptível de tudo que está presente no Universo".

A PNEA propõe, como explica Derani (2011, p 44), "uma educação para a vida" e para outro estilo de vida. Podemos dizer, então, que "a Educação Ambiental é um ensino ético, escudo contra uma pseudoeducação que se resumiria em uma estética ou, o que é muito mais perverso, numa retórica da práxis ambiental" (DERANI, 2011, p. 44).

Tendo analisado os aspectos legais que constituem a PNEA e os aparatos constitucionais que tratam de assegurar um tratamento mais cuidadoso ao meio ambiente, cumpre, no próximo tópico deste estudo, adentrar especificamente à Educação Ambiental, como uma forma de racionalizar os saberes ambientais.

\section{Educação Ambiental: racionalização dos saberes ambientais}

A Educação Ambiental, enquanto direito do estudante, e dever de diversos atores sociais, ainda que devidamente legislada, exige uma série de novas concepções, que devem ser repensadas dia após dia.

Assim, a consciência da interdependência entre todas as formas de vida faz parte da construção de um novo ser humano, que conhece seu lugar neste planeta e sua capacidade de criação, que implica em maior responsabilidade e cuidado com as demais espécies, por isso "a Educação Ambiental é bem mais que uma legislação” (ALBUQUERQUE; FORTES, 2011, p. 79).

Visão otimista do assunto traz Portanova (2011, p.148) ao afirmar que: 
Claro que uma transformação desta ordem de grandeza, que exija um novo modelo civilizatório e uma nova atitude diante do planeta, não vai se conseguir apenas com um instrumento legal, porém, sem ele, dificilmente será possível fazer avançar a abrangência e dimensão que o tema precisa atingir.

Deste modo, após a apresentação da PNEA, se faz importante estudar a Educação Ambiental em si, como uma ferramenta para atingir a racionalização dos saberes ambientais, desenvolvida por Leff, vista como um objetivo a se atingir. As transformações do conhecimento, induzidas pela construção de uma racionalidade ambiental colocam ênfase na relação que a reconstrução do mundo, exigida pela crise ambiental, mantém com a reconstituição do conhecimento (LEFF, 2011, p.158).

A educação é definida teoricamente como "uma prática social cujo fim é o aprimoramento humano naquilo que pode ser aprendido e recriado a partir dos diferentes saberes existentes em uma cultura, de acordo com as necessidades e exigências de uma sociedade" (LOUREIRO, 2003, p.35).

Por isso, ao pensar em Educação Ambiental, deve-se levar em consideração seu significado político e social no Brasil, afinal, "Educação Ambiental é educação", e assim deve ser compreendida, porque a prática descontextualizada, que desrespeita princípios pedagógicos, acaba por gerar resultados inócuos e até duvidosos em termos qualitativos (LOUREIRO, 2003, p.37).

Por meio de uma conscientização que atinja a todos, a Educação Ambiental tenta ultrapassar a diferença criada entre a natureza e a sociedade, sendo a visão socioambiental um de seus fundamentos, que tende a afirmar o meio ambiente enquanto um espaço de relações e interações, sociais culturais e naturais. A ética ocorre quando tais relações são compreendidas e respeitadas (RODRIGUES; FABRIS, 2011, p.27).

Neste sentido, Leff (2011, p.158-159) explica que "a racionalidade ambiental, como formação social, se constrói a partir de seu discurso teórico, mas se expressa na realidade através de mudanças sociais que se refletem em transformações do conhecimento e suas aplicações em novas formas de organização social e produtiva". Por isso, ela deve ser trabalhada desde o início da vida escolar em escolas abertas e participativas, por meio de um processo educativo de forma ativa e atuante, em que as atividades desenvolvidas permitam a assimilação da conscientização ambiental, enquanto valores muito mais duradouros, diferentemente do que se consegue com a educação tradicional (RODRIGUES, 2011, p. 16-17). Assim, ensina Leff (2011, p.157): 
A transformação do conhecimento a partir dos princípios de racionalidade ambiental é um processo que se defronta com as barreiras teóricas de cada disciplina e com a rigidez institucional das esferas onde funcionam os saberes legitimados, através de uma matriz de interesses opostos, diferenciados e desiguais dos atores que mobilizam e se enfrentam no campo da luta ambiental. Ali os movimentos sociais pela reapropriação de saberes, práticas e estilos de vida tradicionais e alternativos confrontam os paradigmas dominantes das ciências (economicismo, biologismo, energitismo, tecnologismo), e sua vontade cientificistas e tecnocrática para resolver a problemática ambiental.

Conforme Derani (2011, p.53), "a Educação Ambiental deve inspirar um saber ambiental coletivo, amplo, complexo e carburante de uma prática transformadora". A autora exalta que, ainda que ela seja voltada ao sujeito, a Educação Ambiental deve moldar uma aptidão para impulsionar uma normativa do coletivo, afinal, "a educação certamente é para o ser, mas deve ser construída de modo a se mostrar apta a vincular os sujeitos na teia coletiva das relações sociais, e não morrer na consciência isolada do sujeito pensante" (DERANI, 2011, p.53).

A Educação Ambiental almejada, de acordo com Rodrigues e Fabris (2011, p. 36) é aquela que tende a tocar o aluno gradativamente, conscientizando-o sobre o respeito, não só para com a sua cultura e a sua comunidade, mas também a diversidade e o planeta.

O saber ambiental, visado pela Educação Ambiental, introduz, nas palavras de Leff (2011, p. 159) "efeitos epistemológicos (mudanças nos objetos de conhecimento), teóricos (mudanças nos paradigmas de conhecimento) e metodológicos (interdisciplinaridade, sistemas complexos)".

Dentro deste amplo cenário, e no que concerne à interface cidadaniameio ambiente, pode-se definir a Educação Ambiental como "uma práxis educativa que tem por finalidade a construção de valores, conceitos, habilidades e atitudes capazes de possibilitar o entendimento da realidade de vida e a atuação lúcida e responsável de atores sociais individuais e coletivos no ambiente [...] de modo que um novo padrão civilizacional é implementado, diferentemente do vigente, e pautado numa nova ética da relação sociedadenatureza" (LOUREIRO, 2003, p.38).

As novas atitudes fomentadas nos sujeitos sociais pela Educação Ambiental estabelecem novos critérios de tomada de decisões, o que implica em educar para formar um pensamento crítico, criativo e prospectivo, que possa analisar as complexas relações existentes entre os processos naturais e sociais, e atuar no ambiente com uma perspectiva global, mas que ainda faça a diferenciação entre as diversas condições naturais e culturais que o definem (LEFF, 2011, p.256). 
Também pelo grande desafio a ser enfrentado pela Educação Ambiental, é que, conforme Derani (2011, p.45), há uma indisposição para enquadrar a Educação Ambiental em uma disciplina específica, porque a questão ambiental é transversal, e "só poderá ser a educação do comportamento humano sobre $o$ ambiente". Por isso, "um desafio da Educação Ambiental é construir uma ressignificação da vida, em um processo de reconstrução de relacionamentos com o meio com base em valores e objetivos responsáveis e solidários com o movimento do todo" (DERANI, 2011, p.54).

Ao incorporar a racionalidade ambiental ao processo de ensinoaprendizagem, se exerce o rompimento do "edifício do conhecimento e do sistema educacional", enquanto integrante do aparelho ideológico do Estado que tende a reproduzir um modelo social desigual, insustentável e autoritário, e formar ideologias que resultam em sujeitos sociais que se ajustem às estruturas sociais dominantes (LEFF, 2011, p.256).

Neste sentido, a Educação Ambiental é uma educação para a vida e para a recepção da vida, sendo que a manutenção e a reprodução da mesma exigem o exercício de uma razão livre do aprisionamento do Estado e do Mercado, que, no passado, representavam ao homem a segurança de sua curta existência (DERANI, 2011, p.58-59).

Conta-se, portanto, com o necessário papel do professor ambiental, que não é o professor de uma disciplina específica, mas que, por meio da transdisciplinaridade, visa criar essa racionalidade e consciência ambiental, em qualquer matéria ministrada.

Rodrigues e Fabris (2011, p.35-36), ensinam que cabe ao professor mostrar aos seus alunos fatores que contribuam na preservação do meio ambiente, instigando-os a raciocinar sobre a sociedade e o consumismo desenfreado, para que possam se atentar às suas próprias responsabilidades. Assim, torna-se importante apresentar aos alunos questões mais próximas, para que colaborem de forma consciente e atuante (RODRIGUES; FABRIS, 2011, p 33).

O papel do educador ambiental, para Portanova (2011, p.168) não é apenas ensinar para quem precisa saber, mas estar aberto a novos conhecimentos, abandonando sua condição de acadêmico puro e livre de contaminação pelo seu objeto de estudo.

Tendo entendido a racionalidade que se busca por meio da PNEA, e visualizado que a Educação Ambiental é muito mais que uma simples legislação, que ainda não encontra diretrizes claras, e exige do educador uma postura flexível e atuante, cumpre, no próximo passo do presente estudo, contextualizar a ideia do consumidor cidadão, como resultado esperado de uma educação voltada à responsabilidade e à sustentabilidade ambiental. 


\section{A cidadania e o consumo}

É comum, coloquialmente falando, que, ao pensar em cidadania, automaticamente voltemos nosso raciocínio ao direito ao voto, não considerando tantas outras interfaces que nos fazem cidadãos. Essa ideia, ainda que de forma subjetiva, nos mantém em uma posição passiva em relação aos acontecimentos sociais, como se escolher um representante fosse suficiente à cidadania. Este tópico, então, tem o intuito de apresentar novas concepções de cidadania, que vinculam o ser ao papel atuante do consumo, voltado à sua responsabilidade social e ambiental, um ser que, na visão deste trabalho, só pode ser construído por meio de uma Educação Ambiental de qualidade.

Para tanto, é necessário entender que, conforme Araújo (2015, p.273), a Educação Ambiental é um meio de grande eficácia para a formação de uma postura responsável no consumo, sendo que tal mudança de postura se tornou imprescindível para a sustentação dos recursos naturais na produção e pela própria preservação dos mesmos. Destacando que a preservação não é apenas para que o sistema de produção se mantenha, mas, como prevê o dispositivo constitucional, para que o meio ambiente reste protegido $\mathrm{e}$ reservado para as futuras gerações (ARAÚJO, 2015, p.273).

O Código de Defesa do Consumidor ${ }^{17}$ garante como direito básico do consumidor "a educação e divulgação sobre o consumo adequado dos produtos e serviços, asseguradas a liberdade de escolha e a igualdade nas contratações" (art. 6을 inciso II). Mais adiante se vê que o acesso a qualquer informação acerca do produto ou serviço que adquire não somente é um direito garantido ao consumidor, como também se qualifica como obrigação do fornecedor (art. 31). Neste sentido, bem coloca Araújo (2015, p.273):

O consumidor tem direito de optar por um produto que seja ou não menos danoso ao meio ambiente, e essa opção só será benéfica ao meio ambiente se houver uma preparação do consumidor [...] é muito mais do que ter direito à informação sobre o produto, mas ter a consciência de que tal produto é danoso ou apresenta riscos ao meio ambiente e que essa consciência influencie na escolha.

Assim, a Educação Ambiental, estudada no tópico anterior, é posta como válvula propulsora da mudança de comportamento. A educação nas sociedades, até o início da modernidade, conforme explica Loureiro (2003, p.36), servia somente aos nobres, possuidores de "direitos divinos", o que teve mudanças significativas a partir do século XVII.

A educação começou a objetivar então, não apenas a formação do indivíduo para o convívio social e para o trabalho, mas para "formá-lo como 
cidadão ativo, sujeito capaz de conviver em sociedade", o que implica em "decidir sobre como deve ser a sociedade em que se quer viver". Deste momento em diante o cidadão deixou de ser a elite e passou a ser qualquer indivíduo, agente de transformações da história (LOUREIRO, 2003, p.36).

Destaca-se a harmonia entre as legislações consumerista e ambiental, já que, conforme atenta Araújo (2015, p.282) ambas buscam, dentre outros objetivos, a proteção da saúde e do bem-estar da sociedade, mas uma se utiliza da definição "consumidor" enquanto a outra utiliza o termo "todos".

É notório que, com a mudança na estrutura da sociedade, o consumo tenha migrado de necessidade para uma atividade comum ao ser humano. Esta mudança, para Bauman (2008, p.42), é a troca de uma sociedade de produtores, para uma sociedade de consumidores, que tem como núcleo central a felicidade vinculada ao ato de consumir. Assim, para Beck a sociedade industrial transformou-se involuntariamente numa sociedade de risco na medida em que produz sistematicamente novos perigos e se inclina mais além do limite do assegurável (BECK, 2002, p.121), para lidar com esses novos riscos, é necessária uma nova compreensão de cidadania, vinculada ao ato de consumir.

Conforme explica Loureiro (2003, p. 42-43), a cidadania se constrói permanentemente e se constitui ao significar o pertencimento do indivíduo a uma sociedade. O desafio, conforme 0 autor, reside na capacidade de estabelecer práticas democráticas cotidianas, promovendo um ensino capaz de levar o aluno a refletir sobre seu ambiente de vida.

Neste contexto, surgem classificações de consumidores, ou, talvez seja melhor dizer, de comportamentos de consumidores, tais como o consumidor verde e o consumidor sustentável, que serão conceituados na sequência.

O primeiro deles, o "consumidor verde", tem sua ação voltada à opção por produtos e/ou serviços que sejam menos danosos ao meio ambiente, ou que, preferencialmente, não lhe causem danos, ele se caracteriza, portanto, no foco na informação (ARAÚJO, 2015, p.282- 283). Um ponto positivo a ser ressaltado, é que essa atitude pode forçar os fornecedores a oferecerem produtos dessa natureza no mercado (ARAÚJO, 2015, p.282). Porém, há uma severa crítica em tal comportamento "verde", porque, ainda que seja preciso incentivar o consumo de produtos e serviços ecologicamente responsáveis, é mais necessário ainda que se modifique a forma de consumo como um todo, desde o adquirir o produto até o descarte. Além disso, esse tipo de consumidor também deixa de observar pontos imprescindíveis para a sustentabilidade ambiental, como a redução do consumo e a descartabilidade do produto (ARAÚJO, 2015, p. 283-285).

Avançando a análise, o segundo deles, o "consumidor sustentável" se caracteriza pela capacidade de atingir um padrão de consumo e tentar transformá-lo (ARAUJO, 2015, p.286). Esse padrão de consumo pode-se definir pelo uso de serviços e produtos correlatos, que, além de preencherem as necessidades básicas e darem uma melhor qualidade de vida, também

revista brasileira educação ambiental 
reduzem o uso de recursos naturais e de substâncias tóxicas (ARAÚJO, 2015, p.286), além de observarem, tanto que possível, todas as etapas do consumo, ou seja, a compra, o uso, o estoque e o descarte, entre outras. Essa forma de consumo é, conforme Araújo (2015, p.287), a mais indicada, "já que qualquer pessoa tem obrigação de preservar o meio ambiente e, enquanto consumidor está usufruindo dos recursos ambientais, devendo procurar fazê-lo de forma responsável".

Além das citadas categoriais, ressalta-se a incapacidade de dissociar o papel "consumidor", do "cidadão", já que ambos os papeis estão atrelados nos mesmos indivíduos, membros da nossa sociedade, porque, quando migramos de uma sociedade produtora, a uma consumidora, recorremos ao consumo até mesmo para as nossas necessidades básicas de saúde e alimentação. Cada vez mais, as nossas relações interpessoais, são relações de consumo.

Por isso, cabe recordar que, atualmente o Estado-Nação em que se insere o cidadão (consumidor), não mais limita o conceito de cidadania, porque este envolve complexos conjuntos de direitos e responsabilidades sociais, que são produzidos e reproduzidos em sentido global (LOUREIRO, 2003, p.43). Assim, "o conceito de cidadania, além dos aspectos relativos ao acesso e uso de bens e riquezas produzidos e da participação política na definição do que é comum, possui um terceiro componente: o consumidor livre e racional em suas opções, e exigente quanto à qualidade do que adquire" (LOUREIRO, 2003, p.43-44).

Assim, o autor (LOUREIRO, 2003, p.43), esclarece que os conceitos de Ecocidadania, cidadania planetária ou cidadania ecológica são os que traduzem a referida inserção da ética ecológica no cotidiano, possibilitando a tomada de consciência individual e coletiva das responsabilidades locais (a exemplo do consumo) e globais (a exemplo dos danos ambientais), por meio do respeito à vida e a defesa do direito em um mundo sem fronteiras geopolíticas, ampliando-se assim o sentimento de pertencimento à humanidade e a um planeta único.

Ainda, no que concerne às dimensões do exercício da cidadania e sua relação com os comportamentos de consumo, destaca-se:

Há de se ter uma permanente preocupação em manter equilibradas as três dimensões do exercício da cidadania. Os direitos individuais devem estar acoplados aos sociais e ao bem comum. Além disso, os limites que o ambiente impõe e a impossibilidade de expandir a todos o conforto que os bens de consumo propiciam, geram uma necessária compreensão solidária e coletiva que muitas vezes os enfoques individualistas do cidadão-consumidor ignoram. $O$ dado de realidade preocupante é que o aumento hipotético de liberdade pessoal, em função do acesso às informações e de poder de escolha individual, coincide com o aumento da fragilização do poder de decisão pelo coletivo (LOUREIRO, 2003, p.44).

Revbea, São Paulo, V. 13, № 1: 124-139, 2018. 
A cidadania ambiental deve operar concomitantemente em dois níveis principais, o individual, orientando o uso ideal do meio, e no nível coletivo, com o auxílio da racionalização ambiental na utilização dos recursos naturais e do meio como um todo (FERRACINI, 2009, p.47-48).

O cidadão, agora agente de mudanças que incorpora o papel de consumidor, tende (ou deve) a estar cada vez mais atento ao que consome, pois, a priori tem conhecimento dos impactos de suas atitudes no ato do consumo, mudança de postura que é decisiva para a preservação do meio ambiente para esta, e as futuras gerações (ARAÚJO, 2015, p.286). A autora ainda reitera a importância da Educação Ambiental à medida que a população desenvolve 0 discernimento necessário à uma postura consumerista ambientalmente responsável.

Tal mudança comportamental é determinante para os esforços de sustentabilidade do planeta, tendo em vista que 0 ato de consumir não gera apenas uma intervenção no meio ambiente, pois no processo completo de consumo, cada etapa gera intervenções, especialmente 0 descarte nos produtos.

A mudança comportamental aqui referida é aquela que aproxima o cidadão do consumidor, e que, por meio de uma Educação Ambiental de qualidade, que observe os princípios e objetivos da PNEA, possa unificar esses papeis, construindo um consumidor-cidadão que tenha 0 discernimento necessário para consumir com responsabilidade, ciente do seu papel na degradação e na preservação ambiental.

\section{Conclusões}

O consumo é um ato corriqueiro em nossa sociedade ocidental, do modo que os papeis de "cidadão" e de "consumidor", de forma alguma, podem ser dissociados.

$\mathrm{Na}$ sociedade de risco em que vivemos, é necessário formar consumidores cidadãos conscientes dos impactos de seu consumo no meio ambiente, para tanto, é necessária uma Educação Ambiental que obedeça aos princípios e objetivos constantes na Política Nacional da Educação Ambiental, que vise uma racionalização dos "saberes ambientais", enfatizando a relação entre a reconstrução do mundo e a reconstituição do conhecimento.

De todos os princípios listados na PNEA, destaca-se que a Educação Ambiental deve ter abrangência inter, multi e transdisciplinar, assim, a Educação Ambiental não é enquadrada em uma matéria específica, mas permeia todos os campos do saber, desde a educação infantil até a pósgraduação, quando formal, e todos os demais campos da sociedade, quando não-formal. Essa abrangência exige, além de outros fatores, uma postura flexível e curiosa por parte do educador ambiental.

A Educação Ambiental é uma educação para a vida, com o intuito de formar a consciência necessária à ética na relação entre o ser humano e o seu 
meio, especialmente 0 ambiental, com base em valores e objetivos responsáveis e solidários com o movimento do todo.

Neste processo, surgem mudanças comportamentais dos consumidores, que passam a se encaixar em novas terminologias, tais quais: "consumidor verde" e "consumidor sustentável", o primeiro caracterizado pela consciência de escolha, o segundo, pela consciência de todas as etapas do consumo, incluindo, e enfatizando, o descarte. Porém, em uma análise mais aprofundada entre cidadania e consumo, nota-se um novo comportamento, advindo de um componente da cidadania, a liberdade e a racionalização das opções de compra, e a exigência quanto à qualidade do que se adquire, o que caracteriza o assim denominado "consumidor-cidadão", que não deixa de ser um "ecoconsumidor", na medida em que se vê como parte do todo global.

\section{Referências}

ALBUQUERQUE, L.; FORTES, R.M. Ecologismo do ensino: da teoria à práxis in RODRIGUES, H.W.; DERANI, C. (org.). Educação Ambiental. Coleção: Pensando o Direito no Século XXI. Vol. I. Florianópolis: Editora Fundação Boiteux, 2011. Disponível em <http://funjab.ufsc.br/wp/?page id=1819>. Acesso em: 25/04/2017.

ARAÚJO, K.L. Consumo, meio ambiente e sustentabilidade: um olhar sobre o saber ambiental segundo Leff In: DA CUNHA, B.P. et al. Os saberes ambientais, sustentabilidade e olhar jurídico: visitando a obra de Enrique Leff. Caxias do Sul: Educs, 2015.

BAUMAN, Z. Vida para consumo: a transformação das pessoas em mercadoria. Rio de Janeiro: Zahar, 2008.

BECK, U. La sociedad del riesgo global. Madrid: Siglo Veintiuno de España Editores S.A., 2002.

BENJAMIN, A.H. Constitucionalização do ambiente e ecologização da constituição brasileira. In: CANOTILHO, J.J.G.; LEITE, J.R.M. (org.). Direito constitucional ambiental brasileiro. 5 ed. São Paulo: Saraiva, 2012.

BRASIL. Constituição (1988). Constituição da República Federativa do Brasil. Brasília, DF: Senado Federal: Centro Gráfico, 1988.

BRASIL. Lei n. 8.078 de 11/09/1990. Código de Defesa do Consumidor.

BRASIL, Lei 9.394 de 20/12/1996. Diretrizes e bases da educação nacional.

BRASIL. Lei n. 9.795, de 27/04/1999. Educação Ambiental e Política Nacional de Educação Ambiental.

DERANI, C. Educação Ambiental - Um processo acadêmico? In: RODRIGUES, H.W.; DERANI, C. (org.). Educação Ambiental. Coleção: Pensando o Direito no Século XXI. Vol. I. Florianópolis: Editora Fundação Boiteux, 2011. Disponível em <http://funjab.ufsc.br/wp/?page id=1819 > Acesso em: 25/04/2017.

Revbea, São Paulo, V. 13, № 1: 124-139, 2018. 
FERRACINI, M.W. Consciência e Educação Ambiental: um quase experimento no Curso de Direito da UFSC. 169 f. Dissertação (Mestrado) - Universidade Federal de Santa Catarina, Centro de Ciências Jurídicas, Programa de PósGraduação em Direito, Florianópolis, 2009. Disponível em < http://www.tede.ufsc.br/teses/PDPC0929-D.pdf>. Acesso em: 02 mai. 2017.

LEITE, J.R.M. Sociedade de risco e estado. In: CANOTILHO, J.J.G.; LEITE, J.R.M. (org.). Direito constitucional ambiental brasileiro. 5 ed. São Paulo: Saraiva, 2012 (p. 157- 232).

LEFF, E. Saber ambiental: sustentabilidade, racionalidade, complexidade, poder. Tradução de Lúcia Mathilde Endlich Orth. 8 ed. Petrópolis, RJ: Vozes, 2011.

LOUREIRO, C.F.B. (org.). Cidadania e meio ambiente. Salvador: Centro de Recursos Ambientais: 2003.

PORTANOVA, R.S. Educação Ambiental e educação planetária. In: RODRIGUES, H.W.; DERANI, C. (org.). Educação Ambiental. Coleção: Pensando o Direito no Século XXI. Vol. I. Florianópolis: Editora Fundação Boiteux, 2011. Disponível em <http://funjab.ufsc.br/wp/?page id=1819 > Acesso em: 25/04/2017.

RODRIGUES, H.W.; FABRIS, M.W.F. Educação Ambiental no Brasil: obrigatoriedade, princípios e outras questões pertinentes. In: RODRIGUES, H.W.; DERANI, C. (org.). Educação Ambiental. Coleção: Pensando o Direito no Século XXI. Vol. I. Florianópolis: Editora Fundação Boiteux, 2011. Disponível em <http://funjab.ufsc.br/wp/?page id=1819> Acesso em: 25/04/2017. 